\title{
TEMPORARY EMERGENCY SHELTER AGARIYAS: A CASE STUDY FROM THE FLOOD PRONE SITE OF KUMANO, JAPAN
}

\author{
C. Ochiai ${ }^{1, *}$ \\ ${ }^{1}$ Graduate School of Global Environmental Studies, Kyoto University, Japan - ochiai.chiho.2x @kyoto-u.ac.jp
}

Commission II - WG II/8

KEYWORDS: Flood Preparedness, Temporary Shelter, Architectural Features, Local Knowledge, Self-effort

\begin{abstract}
:
This study clarifies different issues associated with temporary emergency shelters called Agariyas during floods, in the Kumano, area along the Kumano River in Wakayama Prefecture, Japan. The locations and features of Agariyas were identified through fieldwork. To collect and confirm the location and past existences of Agariyas, interviews were conducted with the elderly. Also, a measurement survey was used to collect data on the types, location, floor plan, and material use of Agariyas. The study confirmed that many Agariyas were built after the 1889 flood, the water level of which influenced their locations. However, currently, very few remain. They were mainly minimally furnished with one to two rooms, a storage space, and a small kitchen for a temporary evacuation period. They were built on terraces or mounded ground. Their architectural features differ depending on the owner, but they were most commonly built using wood, and the roof was covered with cedar bark and rounded stones. Younger generations do not know about Agariyas. To increase the local knowledge and awareness of flood disaster culture, it is important to re-evaluate the tangible and intangible heritage in local communities, which includes the effort and wisdom of ancestors related to local disasters. The Kumano-Hongu Shrine and pilgrimage route attract visitors today. However, addressing the experiences and knowledge of local disaster may add value to the World Heritage site.
\end{abstract}

\section{INTRODUCTION}

\subsection{Background of the study}

In recent years, the flooding of rivers from record torrential rain and the discharge of dams have caused enormous damage to people and settlements physically, economically, and socially. People's lives and settlements have always been affected by natural disasters, and they have coped by changing their settlement, constructing structures, and developing local knowledge and wisdom for disaster management culture. People who live near the river practiced "living with floods" for many years.

Natural disasters have a major impact on people's lives, buildings, and landscapes of settlements. For example, where floods frequently occur in Japan, ring-filling banks (Waju) and water protection houses (Mizuya) in the Kiso-river basin are known as traditional flood measures. Similarly, in the case of riverbanks and architecture, there are changes in their shapes and names throughout Japan. According to the "list of traditional river technology database" by the Ministry of Land, Infrastructure, Transport and Tourism (MLIT), there are several flood prevention/preparedness structures in 26 areas that are registered near rivers across the country. Many are called Mizuya, Mizukura, Dankura, and Mizuzuka (Ministry of Land, Infrastructure, Transport and Tourism, 2015; Tada et al., 2013; Uchida and Nakai, 1964) ${ }^{1}$.

In the research of flood prevention/preparedness architecture, spatial design, architectural characteristics, and the relationships between villagers and such architecture are studied and analyzed in major river basins famous for flood disasters in Japan (Kido and Suzumura, 1951; Ando, 1990; Aoki and Kuroyanagi, 2015).

\footnotetext{
* Corresponding author.

${ }_{1}$ Mizu means water, Dan means step or stair, Kura is storage house, $Y a$ is house. All have slightly different architectural or basement features.
}

Some studies demonstrate the effectiveness of traditional techniques and the importance of the involvement of local organizations engaged in flood prevention/preparedness (Harima and Kuroyanagi, 2003). The study of flood-related architecture in the Yodo and Kiso rivers concluded that traditional flood control methods against inundation and flood were useful (Ishigaki, 2002). It has been shown that flood protection/preparedness architecture built in the areas has accumulated flood control knowledge, and this wisdom has been inherited by the succeeding generations (Ishigaki, 2002; Miyamura, 2010).

In flood-prone areas, people have been plagued yearly by flood damage, and large floods happened once every several years. Public projects, such as raising riverbeds, revetment maintenance, dam construction, and river dredging projects have occurred to improve living conditions and safety. These developments in the regular flood-prone area have brought great changes in housing styles and people's awareness.

Miyamura argued that flood prevention architecture based on the regional characteristics and empirical rules in each area has coped with disasters. However, in the post-war period, the public works improvement of flood controls and the reduction of disaster changes has led to the decline and undermining of those traditional and regional architectural flood prevention/preparedness measures. Miyamura stated that "their traditions are now disappearing in modern rational thought" (Miyamura, 2010) 
By considering such a background, this research records and elucidates how flood prevention/preparedness architecture was built in flood-prone areas, as well as how the settlement locations, housing styles, and people's disaster awareness and recognition changed. Developing a program to inherit the disaster culture is needed because it is important to increase the awareness and knowledge of local natural disasters among local people.

\subsection{Purpose of the study}

This study focuses on different issues related to Agariyas. First, it defines their geographical distribution and layout in Hongu-cho (town). Second, the detailed location and social background concerning this flood prevention/preparedness architecture will be studied in the Hongu area of Hongu-cho. Third, this study explores how the public and the next generations can inherit this traditional knowledge and their remnants. Finally, this study considers the possibilities for future generations.

There are scant written documents on Agariyas because of repeated floods and the merger of municipalities. According to local governments and people, no research has documented them. The author confirmed the present existence of Agariyas from the residents and investigated it in detail while researching the evacuation behavior of local people at the time of the large 2011 flood in this area.

\subsection{Methodology}

Research on Agariyas was conducted first by a bibliographical survey of prefectural, city, and town histories, among others. In prefectures and municipalities along the Kumano River basin, administrative officers and residents were interviewed. Several interviews confirmed the existence of Agariyas in Hongu-cho (in the past, it was an independent village but is now a district of Tanabe City) and also in some other villages along the Kumano River. A detailed survey was conducted in the Hongu area of Hongu-cho, where Kumano-Hongu-Taisha (a shrine) is located. The location of Hongu-cho is shown in Figure 1.

The residents were repeatedly interviewed, and photos taken during floods and housing-related documents (administrative data such as resident register) were also collected. In the measurement survey, information related to the layout, floor plan, and elevation of Agariyas were collected. At this time, information about Agariyas owned by each household, and their spatial relationship with the houses, was confirmed. The summary of the study methods and period is shown in Table 1 .

\section{OUTLINE OF STUDY AREA AND FLOOD EXPERIENCES}

\subsection{Natural and social characteristics}

The catchment of the Kumano River is one of Japan's heavy rain areas. It is geographically located in the hilly area and surrounded by the Kii Mountains with an annual rainfall of over $4000 \mathrm{~mm}$. There are few open plains along the Kumano River, and houses are densely populated on a few plains along the river and hill slopes. Since each village is formed at the junction of rivers, this area has been flood-prone since ancient times.

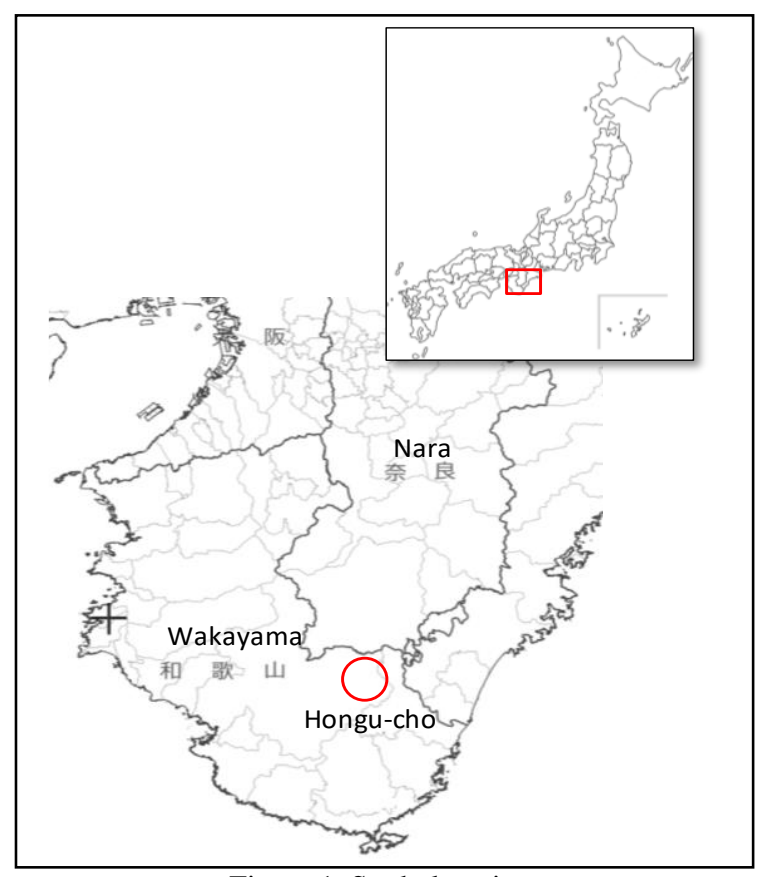

Figure 1. Study location

\begin{tabular}{|l|l|}
\hline Year & Research activity \\
\hline 2012 & Flood evacuation situation and damage \\
\hline 2014 & $\begin{array}{l}\text { Interview to find Agariyas; Measurement } \\
\text { and owner interviews }\end{array}$ \\
\hline $2016-2018$ & $\begin{array}{l}\text { Agariya measurement in detail; } \\
\text { Educational town walks to visit Agariyas } \\
\text { and other flood-related monuments }\end{array}$ \\
\hline
\end{tabular}

Table 1. Study method and period

This area is registered as one of the "Sacred Sites and Pilgrimage Routes in the Kii Mountain Range" (UNESCO, 2019) in the UNESCO World Heritage Site 2007. Therefore, it attracts visitors across Japan, who come there to offer prayers at the Kumano-Hongu-Taisha. Historically, this pilgrimage route became very popular in the Heian to Edo periods (around the eighth to eighteenth centuries); however, thereafter, it lost its popularity and was almost forgotten by the public. Currently, the pilgrimage route is known worldwide, attracting many international hikers.

This area flourished economically because of the Kumano River's wood production from an upstream area of Totsukawa Village to Shingu City (located at the mouth of the Kumano river). Also, in the Taisho era (the early 1900s), propeller vessels operated (Hongu-cho, 2004) between Totsukawa, via Hongu, and Shingu. During that time, many residents and tourists used it as a means of transportation, and it played an important role as a river highway, bringing prosperity to the area. However, in the 1950s, with the construction of electrical power dams and the opening of national roads, the river-based transportation route declined and was replaced by land transportation. Water connected the villages along the Kumano River, and sports and cultural exchanges were popular, but land transportation and administrative marginalization affected their relationship. 
The Hongu area in Hongu-cho is the detailed survey site for this research. According to the Municipal Merger Promotion Act, because of the merger of several villages with Hongu-Village, Hongu Village became a part of Hongu-cho in 1956. Furthermore, when five municipalities were merged in 2005 , Hongu-cho became a part of Tanabe-City. The area covers 204.5 $\mathrm{m}^{2}$, with a forest area of $92.6 \%$ and a residential area of only $0.4 \%$. In this area, Kumano-Hongu Shrine, administrative agencies, and houses are concentrated at National Route 168 along the Kumano River. The mountain slope behind is relatively gentle, though few flat residential lands and houses were built on terraced land with stonewalls. Many stores and inns were located near the entrance of the former location of the Kumano Hongu Shrine as the center of the town. Later, this shrine was moved to its current location, on the top of a hill, after a flood in 1887.

\subsection{Flood history}

The area has been hit by floods several times. Especially in the floods of August 1889, about 1,080 landslides occurred in the upper reaches of Totsukawa Village. These landslides caused many deaths and forced many people to move to Hokkaido (the northern, un-developed land in Japan at that time). The damage at Hongu-cho, which is located at the middle point of the Kumano River, was also severe. The record showed 700 to $1000 \mathrm{~mm}$ of maximum rainfall per day.

Although many floods have been experienced, in the case of the 1953 floods, 193 out of 250 homes were recorded to be damaged, and 22 people were killed, which shows the magnitude of the damage. Hongu-cho's inundation level sometimes reached about $21 \mathrm{~m}$ high. Many parts of the Kumano-Hongu-Taisha buildings were destroyed and washed away by this flood, and it was decided to move the shrine to its present location (the top of a nearby hill). Additionally, one-third of elementary school children had to quit school because of the damage caused to their families. The damage caused by the floods in 1935 and 1953 was also significant. In 1953, the area was affected by heavy rainfall, which affected 4,680 persons. One-hundred and sixty-seven houses were damaged. Several landslides and mudflows occurred (Hongu-cho, 2004).

Furthermore, in 2011, typhoon No. 12 brought heavy rain, which led to landslides and flood. Many houses experienced inundation to the height of the celling of the first floor. Such inundation was caused by a large amount of rainfall but also unexpected amounts of water discharge from an upstream dam, which recorded over $8,918 \mathrm{~m}^{3} / \mathrm{s}$ (Tanabe city, 2011).

\section{OUTLINE, DISTRIBUTION, AND TYPES OF AGARIYAS IN HONGU-CHO}

\subsection{Agariyas}

Agariyas were a shelter for people, goods, and food during and after flood periods, built at a higher location than the houses and stores on the road of the Kumano river. Agari in Japanese means "upper" or "lift," and ya means "house" or "shelter."

A stone stairway is built at a corner of the main building. Types of stone stairway can be divided into two: one built on slightly higher ground behind the main building, and the other built on a hill slightly away from the residential plot where the main building is located. Either way, the location of Agariyas remained in the same area, and many stone stairways were set up on the slope of the mountain behind the main house or across the road.

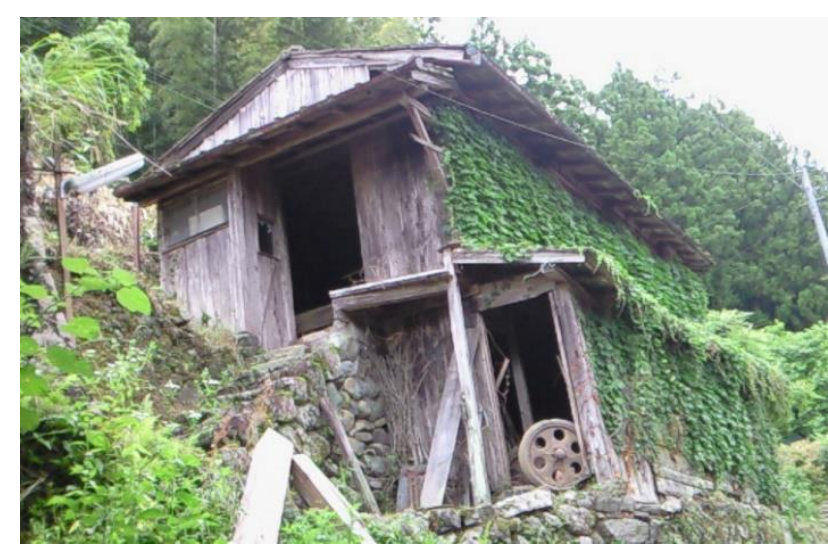

Figure 2. One of the oldest Agariya, in the Ukegawa area in Hongu-cho, destroyed after the flood of 2011.

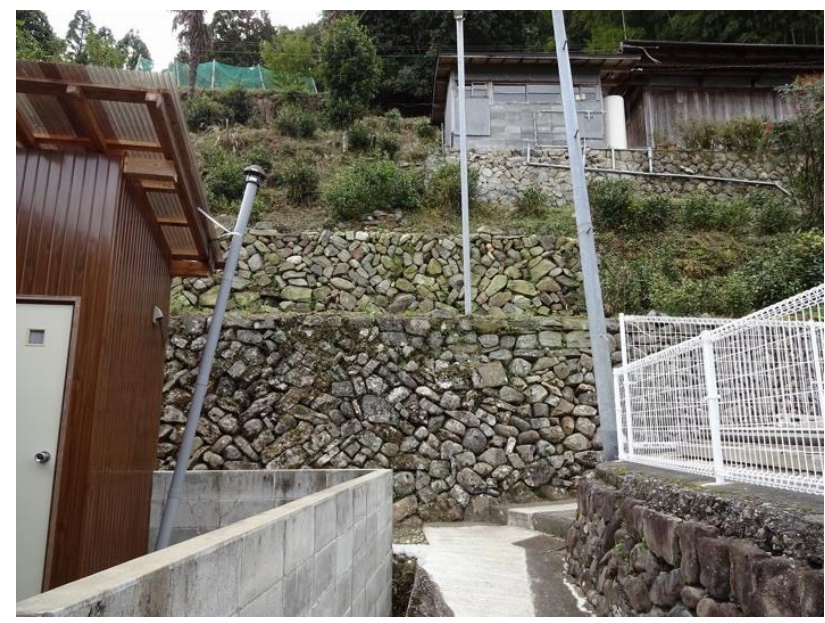

Figure 3. Basement raised and covered by stones of the Agariya in Figure 2.

The Agariyas are owned by house or land owners who run inns or stores and use their Agariyas to store furniture, bedding, goods, clothes and some food during normal times. Agariyas were also used as emergency evacuation shelters during flood disasters. Some residents, including the owner's family, relatives and neighbors, remember spending several days there during and after the severe flood.

The name Agariya is known by residents, but there is no written document to prove what they look like, where they were located, and how they were used. Among the scant details that were officially recorded, Agariyas were described in a few lines in a local history book of Kumanogawa-cho (former town), which is the next village of Hongu-cho (Kumanogawa, 2004).

People living in low lying areas had flood shelters, such as Agariya, especially in the place where the Kumano River and Kitayama River meets. The people in this area had Agariyas a little above Uemura (the name of the local area). Because the surrounding area was in a low-lying area, people were saved by the Agariya, although their houses may have been washed away. At that time, the house was rebuilt at a slightly higher place than the (original location of the) house, which was washed away. To cope with flood damage, we made it twostories, etc. In any case, it was said that houses along the Kumano River went up with each incidence of flood damage. (Kumanogawa town, 2004 p.732-733). *( ) is added, and English translation is made by the author. 
When and how Agariyas began to be built is unknown. However, according to the interview survey of some people in their 70 s or older, they already existed in the Meiji period (from 1868-1912), and it is thought that they were built from the pre-Meiji period to the early years of the Showa period (from 1926 to 1989), from about the late 1800 s to the early 1900 s.

\subsection{Distribution and Types of Agariyas}

During interviews, many Agariyas could not be easily found because of depopulation and aging, or because the owner was not a resident of the area. Furthermore, several stood on the hillside that is now covered by the forest and are inaccessible because of the unstable soil conditions. In recent years, the number of Agariyas has decreased. Additionally, the 2011 typhoon demolished some Agariyas, further reducing their number.

The largest number of Agariyas were found in Ukegawa (15 units), but only three remain, and some are inaccessible. There were ten in Hongu, but only four survive. Furthermore, few remain in Misato in Hongu-cho.

The new road project has changed the current conditions and atmosphere of each area. The households that own Agariyas often have houses and shops along the old main roads, and boats and bus stops used to be located in the nearby area.

When Agariyas located on flat ground were investigated, they were found to have once been built behind houses on slightly higher grounds. The house and Agariya are now built at the same height because in the past the ground was raised by $2-3$ meters in this area to prevent floods.

The businesses of Agariya owners were diverse; they had newspaper, household goods, liquor, or stonemason stores, or owned inns, or were landowners. Moreover, there is no specific style of Agariya; they have a simple housing style with warehouse space. The size of Agariyas varies depending on the owner's economic situation and land ownership and according to whether they are single-story or two-story structures. In recent years, Agariyas have become unoccupied houses, storage facilities, workers' residences, or a rental residence.

\subsection{Agariya classification}

The Agariyas were classified into three types by following the basic classification of other water prevention/preparedness architecture (Ito, 1986). Among the different classifications, A) to C) are shown in Figures 4, 5 and 6.

Residential type (A): This structure has a living room where people can sleep in and it is equipped with facilities such as tatami mats or planks, daylighting windows, living/bedrooms, kitchens, and toilets.

Warehouse type (B): This type stores food (rice, miso, pickled plums, etc.), goods, and household goods (futons, clothes, dishes, etc.). There is almost no daylighting window. It is dark inside; however, during flood times, it can be used as an evacuation shelter.

Residential warehouse-type (C): This is a combination of type $\mathrm{A}$ and type $\mathrm{B}$, being a residential and warehouse-type structure that fulfills both functions. It has a room and a warehouse in the same building.

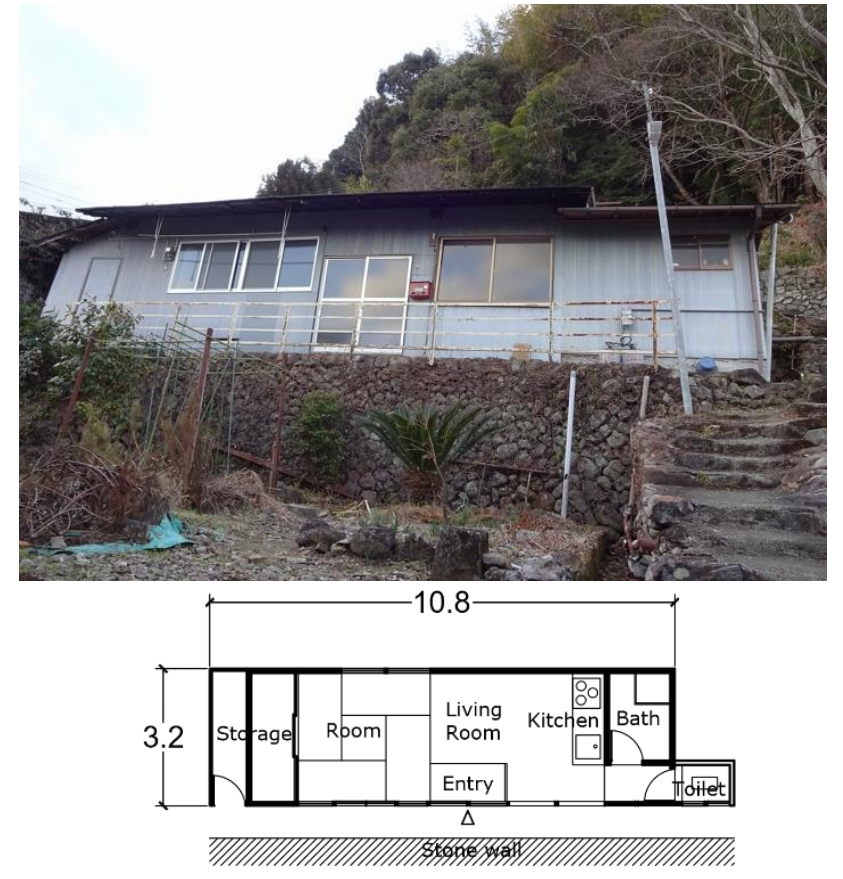

Figure 4. Agariya type A.

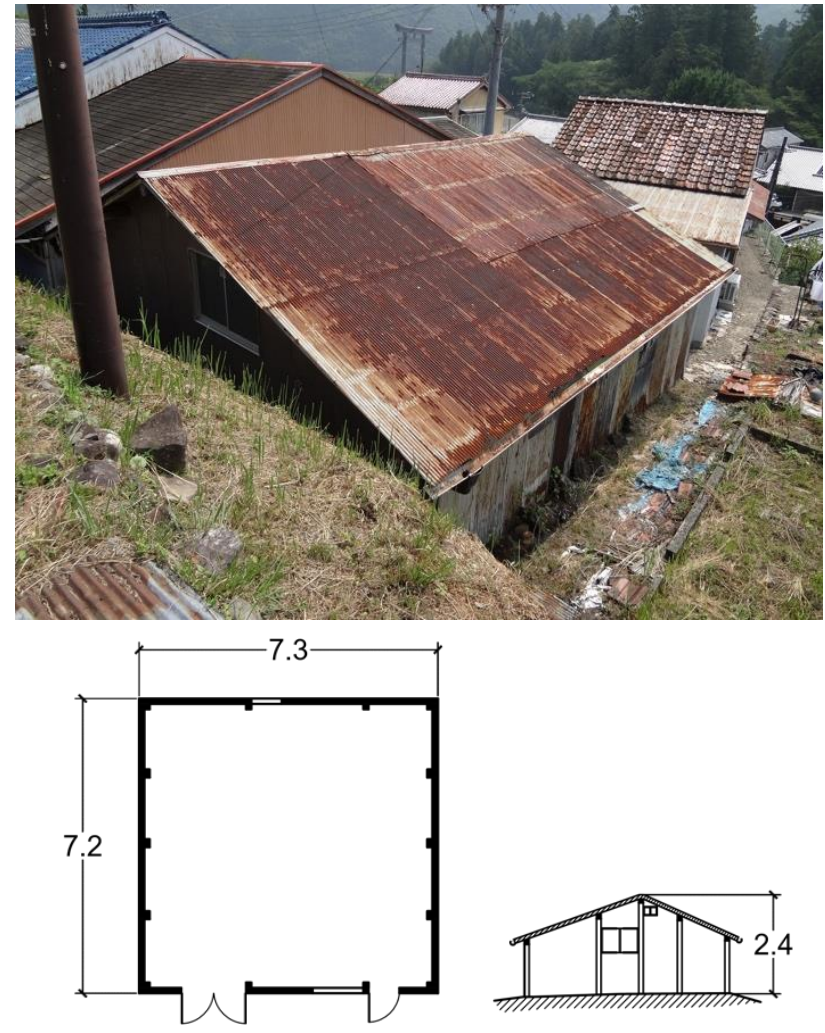

Figure 5. Agariya type B.

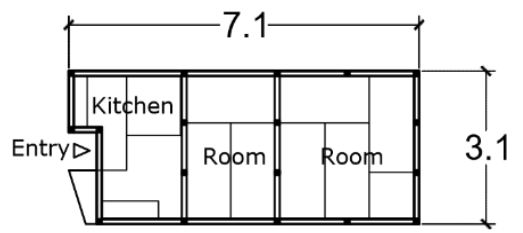

Figure 6. Agariya type C. Agariya of the Figure 2. 


\section{GEOGRAPHICAL AND SPATIAL LOCATION OF AGARIYAS IN HONGU}

\subsection{Village and Agariya arrangement}

In the Hongu area, ten Agariyas can be confirmed in the Iwata and Kamiji neighborhoods. Among those, only four remain. Here, many homes, shops, and Agariyas can be seen along the old road (former main road). Oyunohara's altitude, where the former location of Kumano-Hongu was located (at the central foot of Kumano River), is $51 \mathrm{~m}$. The ground level of the Iwata area and along National Route 168 is about $59 \mathrm{~m}$ in altitude. The average height of Agariyas was about $68 \mathrm{~m}$ in altitude, compared with the average altitude of about $59 \mathrm{~m}$ of shops and houses. The elevation difference between the shops and houses, for Agariya in general, is at least $1 \mathrm{~m}$ and at most about $15 \mathrm{~m}$. The construction of Agariyas occurred mostly after the flood damage of 1889 and 1953 in Hongu. The criteria to determine the construction of Agariyas and the height of the ground that can be confirmed today are greatly related to the flood damage in 1889 and 1953.

The construction time of Agariyas can be roughly divided into before and after the flood of 1953. Additionally, it was confirmed that several buildings were built around 1965 . Different measures were taken after different floods. For example, Figure 7 shows a traditional Agariya in Hongu, which is owned by a clothing store owner (No. 7 in Table 2/Figure 9). The lower part of the stone base was made before 1889 , but it was affected by flood damage in 1953. Therefore, based on the flood water level of 1953 , about $1.3 \mathrm{~m}$ of new stone walls were added to raise its height.

Consequently, there was no damage in the 2011 flood (mentioned by the owner, a man in his 70s), although the residential section in front of it was profoundly affected. Even before the flood in 1889, there was a possibility that Agariyas were like this. Still, people believe that the flood in 1953 opened an opportunity to create many Agariyas in this area. Presently, the exact year of the beginning of Agariya construction cannot be identified.

The typical arrangement examples of houses and Agariyas is shown in Figure 8, which shows the arrangement in the village of Agariyas in a cross-sectional view. The two types are an onsite embankment type and an off-site elevated platform type. In Hongu, both arrangements are confirmed to exist.

\subsection{Usage and change of awareness}

Agariyas were used as storage places during the normal period and floods. Several items such as food, futons, and merchant goods were stored. Many Agariyas had spaces such as living/bedrooms and kitchens, which could be used for evacuation and as temporary shelters after flood damage. Based on the interviews, it can be assumed that the 1889 flood experience inspired local people to construct Agariyas to protect their lives and goods.

Changes in the use of Agariyas have been caused by flood control projects and decreasing chances of flood. The decline of the local population and changes in the owner's occupation also reduced their number. Building structures are another factor behind Agariya loss. Many houses have been built with two stories. The second floor is safe from floods; so, it can be used during a flood, and goods can be regularly stored on the second floor.

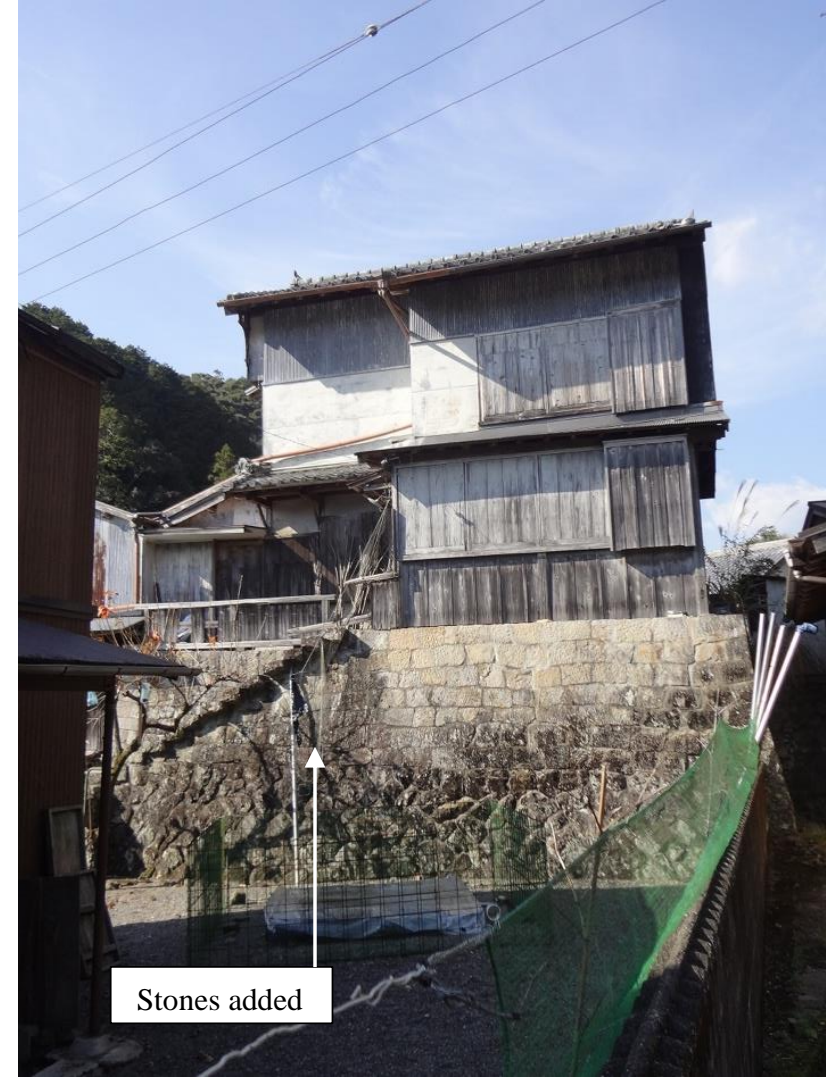

Figure 7. An Agariya still stands in the Hongu area in Hongu-cho.

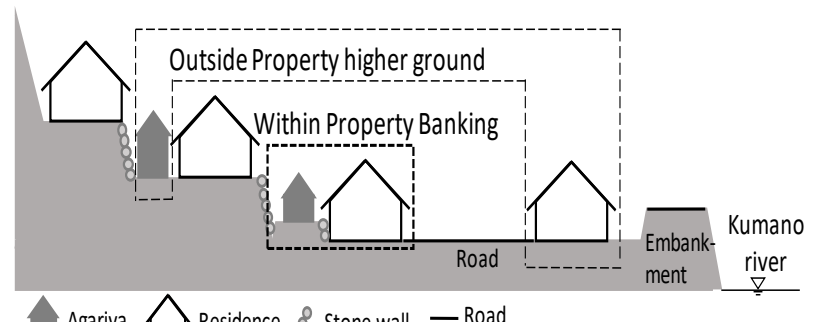

Agariya $\bigcirc$ Residence 8 Stone wall — Road

Figure 8. Arrangement of house and Agariya.

Furthermore, few residents evacuated to Agariyas at the time of the 2011 flood. According to residents, this is because "I could not use it because it was being rented"; "The way to the Agariya was flooded when I was going to evacuate"; "I have not used it for many years," and so on. Therefore, it can be said that few people used Agariyas in 2011 during evacuations. Additionally, flood evacuation places are assigned by local municipal offices; thus, people feel less need to prepare for evacuation on their own.

\section{INHERITING DISASTER MEMORY}

Younger people had not experienced floods before 2011, and many did not know about Agariyas. This section highlights educational town walks, which were conducted to learn about flood-related sites of tangible heritage and people's knowledge and experiences of intangible heritage of disasters. It aims to disseminate knowledge and increase the awareness of people, including local residents and tourists, and incorporate students' feedback of the walk. 


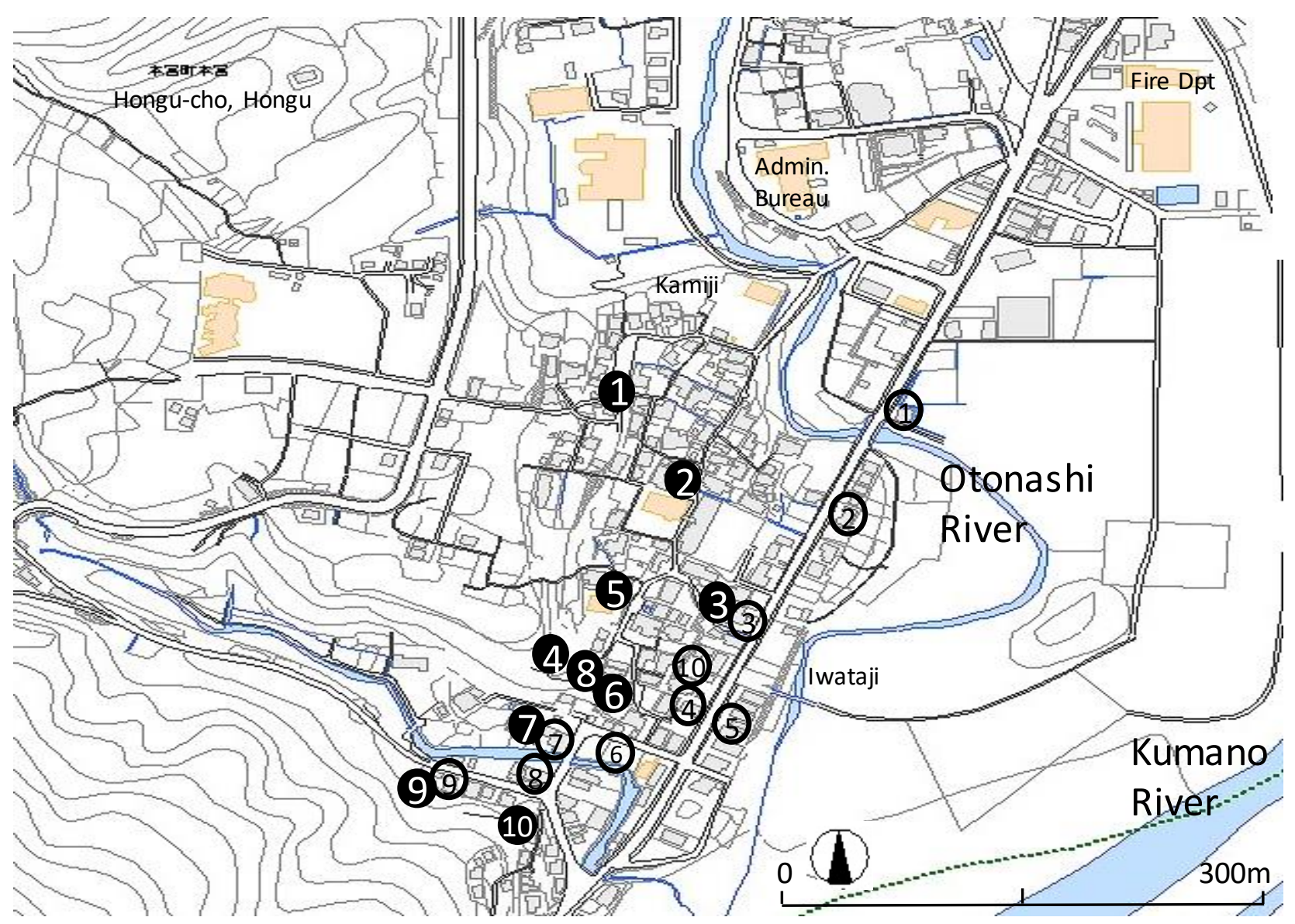

Figure 9. Location of Agariyas and residences in Hongu (Black circles show Agariyas and white circles are houses/shops).

\begin{tabular}{|c|c|c|c|c|c|}
\hline No. & Type & $\begin{array}{c}\text { Year of } \\
\text { construction }\end{array}$ & $\begin{array}{c}\text { Residence/Agariya } \\
\text { Elevation }\end{array}$ & Condition & Outline \\
\hline 1 & Resi./Stor. & Unknown & $58.0 / 71.4(+13.4)$ & Demolished & $\begin{array}{c}\text { Prior owner of restaurant. Agariya became a } \\
\text { residence and was then sold }\end{array}$ \\
\hline 2 & Storage & Unknown & $58.2 / 67.7(+9.5)$ & Exist & $\begin{array}{c}\text { Prior owner of photo studio. Small storage house } \\
\text { next to Elementary School }\end{array}$ \\
\hline 3 & Storage & Before 1953 & $58.9 / 59.7(+0.8)$ & Demolished & $\begin{array}{c}\text { Prior owner of post office. Storage behind building } \\
\text { on the top of mound }\end{array}$ \\
\hline 4 & Storage & Before 1953 & $58.8 / 74.0(+15.2)$ & Exist & Owner of stone shop, used as storage \\
\hline 5 & Storage & Before 1953 & $58.8 / 73.5(+14.7)$ & Demolished & $\begin{array}{c}\text { Prior owner of stone shop, sold to local govt. for a } \\
\text { policeman's residence }\end{array}$ \\
\hline 6 & Resi./Stor. & Unknown & $58.8 / 64.7(+5.9)$ & Demolished & $\begin{array}{c}\text { Prior owner of inn. Had space to store goods. } \\
\text { Recently demolished }\end{array}$ \\
\hline 7 & Resi./Stor. & M.- early T & $58.2 / 59.2(+1.0)$ & Exist & $\begin{array}{c}\text { Agariya located back of house/store. Damaged in the } \\
\text { 1953 flood and elevated about 4m. Used for storage }\end{array}$ \\
\hline 8 & Resi./Stor. & Unknown & $58.8 / 64.3(+5.5)$ & Demolished & $\begin{array}{c}\text { Prior owner of liquor shop. Used for storage. The } \\
\text { shop owner moved to different location. }\end{array}$ \\
\hline 9 & Storage & Around \\
& & 1945 & $72.8 / 76.7(+3.9)$ & Demolished & $\begin{array}{c}\text { Evacuated during the 1953 flood. Leased to dam } \\
\text { construction workers for a few years. Agariya } \text { was } \\
\text { demolished because of less frequent floods after the } \\
\text { dam construction. }\end{array}$ \\
\hline 10 & Resi./Stor. & Unknown & 63.7/66.7 (+3.0) & Exist & $\begin{array}{c}\text { Owned a general store. Previously used for storage } \\
\text { but is a now vacant house }\end{array}$ \\
\hline \multicolumn{7}{|c|}{$\begin{array}{c}\text { Resi./Stor.=Residence/Storage type, Resi.div.=Residence diversion, } \\
\text { M=Meji period (1868-1912), T=Taisho period (1912-1926), Showa period (1926-1989) }\end{array}$} \\
\hline
\end{tabular}

Table 2. Types, levels and current condition of Agariya in Hongu.

\footnotetext{
${ }^{2}$ Elevation information is calculated based on the data provided by the Geography Information Authority of Japan.
} 


\subsection{Educational Town Walk}

Educational town walks or visits to sites with disaster experience enables the observation and investigation of local disasters and their knowledge. To re-evaluate and increase the recognition of the tangible and intangible heritage related to disaster experience, educational town walks were conducted. It may raise local understanding and give additional value to the World Heritage site.

Educational town watching of disaster-related monuments, shrines, and Agariyas was conducted with the international students of Kyoto University (Figure 10). These students are interested in learning Japanese disaster experiences and coping mechanisms. First, the group observed a stone monument that recorded the height of floodwater over different years. One of the oldest of these monuments has a record from 1889. The local municipal office has recently put other year markers in place, each of which shows the height and year of a flood. After noticing how high the water came, the group visited the Agariya shown in Figure 7. The owner of the Agariya explained its construction as his parents and grandparents had told him. In their house, they marked the 2011 flood, about $2.0 \mathrm{~m}$ from the ground.

After learning about the Agariya in Figure 7, and its history, the group walked towards the Oyunohara, where the Kumano-Hongu shrine was originally located. Afterward, the students walked along the Kumano riverbank. The river has almost no water flow at normal times and is filled with sand. However, it easily increases 5-6 m during flood time (Figure 11). To understand how vast the water pressure could be, the group visited the Kumano-Hongu World heritage center. The group also wanted to understand the historical background of the UNESCO heritage site and learn basic knowledge on the Kumano-Hongu shrine. After obtaining this, the group visited the modern KumanoHongu shrine by climbing many steep stairs. During the walking course, basic information about past and recent floods were explained to the students to increase their awareness.

\subsection{Feedback on student's experience}

By participating in the town walk, several students could understand the magnitude of the flood and reflect on experiences in their own countries, such as Thailand and Vietnam, which also experience severe floods. The practical experience of visiting Agariyas enhanced students` analysis and thinking about how to adopt these kinds of traditional measures in their own country.

Although this educational program was only conducted in the last two years, it might possible to increase the sharing of local knowledge between residents and tourists interested in disaster experience in Hongu. Such activities might help to disseminate knowledge and skills to the next generation.

\section{CONCLUSION}

Since rivers were the main means of transportation, settlements were formed along the rivers, and people have taken various flood control measures to live with floods. Before public works by towns and prefectures began, from the Meiji period until the middle of the Showa period, individual efforts were common. The outline, distribution, arrangement, architectural features, style, function, and factors that decreased the use of Agariyas in Hongu are summarized below.

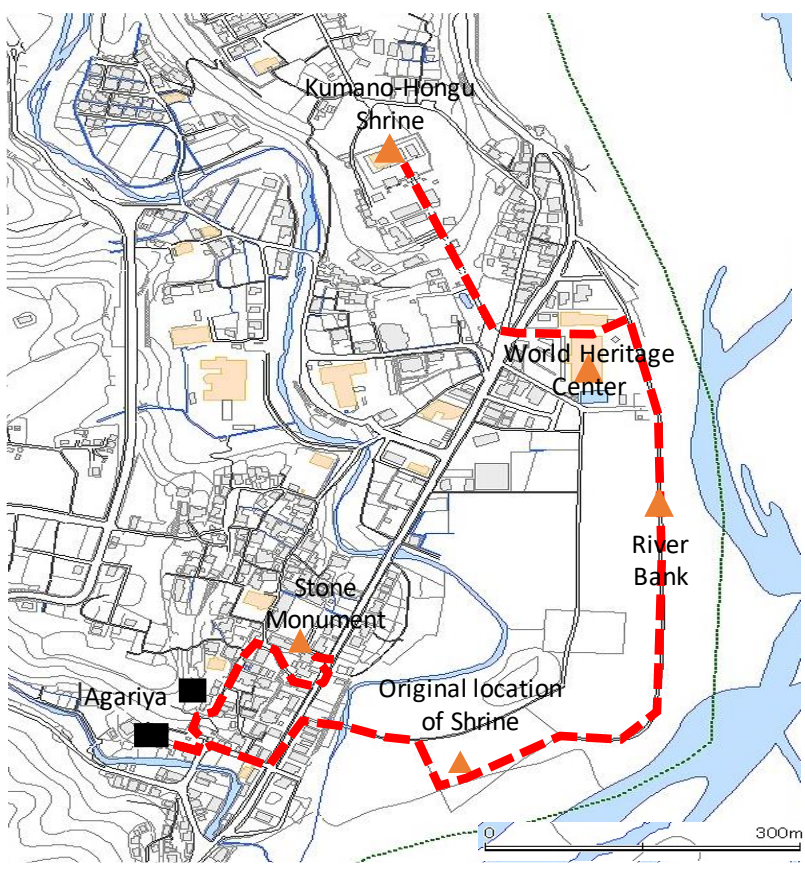

Figure 10. The rout of visiting the disaster remains.

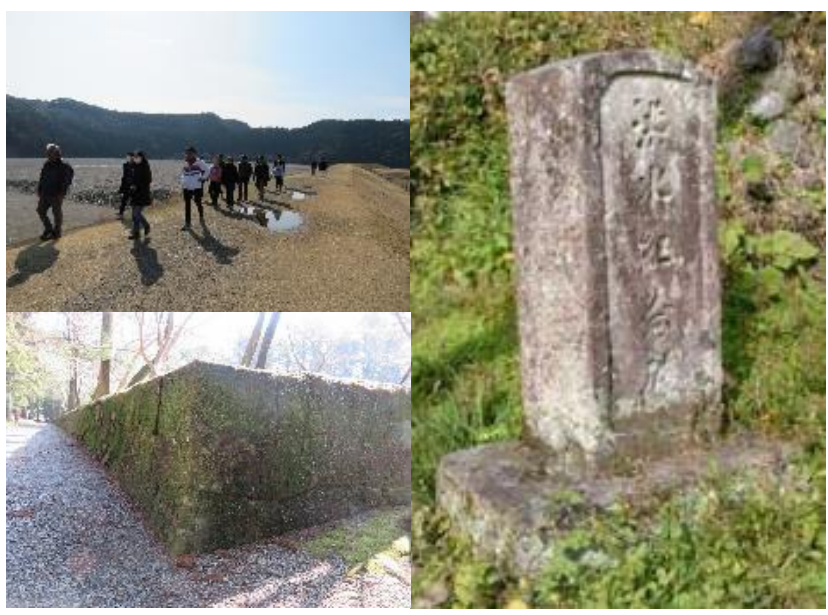

Figure 11. Photos of the disaster remains: a) Kumano Riverbank; b) Original location of Shrine; c) Stone monument.

Agariyas are classified into residential, warehouse, and Residential warehouse types. Whether warehouse or housing types would be more common would be decided by locational factors and the commercial scale of the area.

Agariyas were built as on-site embankment types built on the ground with stone steps, on the back of a house, and off-site elevated types constructed on a hill away from the home. Agariyas were mainly built so that landowners, merchants, and innkeepers could store furniture, bedding, goods, clothes, food, and other important items during floods. They were also used for emergency evacuation during floods. According to the older citizens surveyed, the transition in the use of Agariyas was an adaptation of its original purpose. They were used as residences for families and dam development workers, shelters, and warehouses. 
Agariya use declined without large-scale flooding after 1953 when public works and flood control measures were taken. Damage by flooding decreased with more two-story houses being built. Additionally, there was a change in public consciousness because the creation of public evacuation centers had been promoted and public, rather than private, evacuation was prioritized. Also, due to subsidies for flood-affected houses after 2011, Agariyas (which had deteriorated) were dismantled.

People living in the Kumano River basin have built Agariyas to prepare for flood disasters. Although the flood control project has been promoted to increase safety, it has also led to a decrease in disaster prevention awareness. In 2011, some people evacuated to Agariyas and stayed until their houses were repaired. This proves that hill-side Agariyas are effective, and Agariyas aid the improvement and continuation of disaster prevention awareness for residents.

Younger generations do not know of Agariyas. To increase the local knowledge and awareness of flood disaster management culture, it is important to re-evaluate the tangible and intangible heritage in the local community on local disaster management practices handed down from the ancestors. To help regenerate local traditions and knowledge, the author organized educational town walks visiting Agariyas, stone statues, and former shrine locations over the last two years. Placing Agariyas among those remains might help to conserve them and other floodmanagement relics. The Kumano-Hongu-Taisha and pilgrimage routes are attracting visitors. Furthermore, addressing those disaster experiences and local knowledge is valuable and contributes value to the World Heritage site.

\section{ACKNOWLEDGMENTS}

The author would like to thank the people in Hongu-cho for sharing their knowledge and experiences. Also, the author is thankful to the staff of the general administration division of Hongu-cho in Tanabe city, Wakayama prefecture.

\section{REFERENCES}

Ando Masuo, 1990. Wajutei to mizuya kenchiku, JABS, vol.105, No.1300, pp.42-43 (in Japanese).

Aoki Hidefumi and Kuroyanagi Akio, 2015. Study on the located situation of Mizuya - Mizukura and its transformation in the Arakawa Basin, Japanese Architectural Planning (AIJ) Vol.80, No.710, pp.851-861 (in Japanese).

Harima Hajime and Kuroyanagi Akio, 2003. A study on settlement and architecture of spatial composition and activity of prevention of floods of a flood frequent occurrence zoneComparison of settlement of Tonegawa river and Ibigawa river, Japanese Architectural Planning (AIJ) Vol. 569, pp.101-108 (in Japanese).

Hongu-cho, 2004. History of Hongucho (in Japanese)

Ishigaki Taisuke, 2002. Traditional floor prevention in Yodo river-Effect of Mizuya - Dankura, Kasen 58(11), Japan River Association, pp.27-32 (in Japanese).

Tanabe city, 2011. Memory of Typhoon12 in 2011, Tanabe city, (in Japanese).
Kido Hisashi and Suzumura Tustomu, 1951. Noubi sandaikasen ryuiki niokeru mizuya nit suite: noubi sandaikasenryuiki nougyoukenchiku no kenkyu No.2, Japan architectural association study report (15), pp.63-66 (in Japanese).

Kumanogawa cho, 2004. History of Kumanogawa town (in Japanese).

Ministry of Land, Infrastructure, Transport and Tourism: property management (in Japanese) http://www.mlit.go.jp/river/toukei_chousa/kasen/jiten/nihon_ka wa/86066/86066-1_p4.html2015 (accessed January 2015)

Miyamura Tadashi, 2010. Kaitei Suigai-zchisui to suibou no chie, Kanto-gakuin Uni. publishing (in Japanese).

Tada Yukihiro, Aoki Hidefumu, Kuroyanagi Akio, Tsuboi Sakutaro, 2013. Heisei 25, Nihon University Engineering faculty report, pp.643-644 (in Japanese).

Uchida Hideo, Nakai Minoru, 1964. Kenkyu note "Dankura", Japanese Journal of Human Geography 16-3, pp.90-97 (in Japanese).

UNESCO, available at: https://whc.unesco.org/en/list/1142/(accessed on May 25, 2019)

Yasuo Ito, 1986. Henkasuru Waju, p.24-25, Kokon-shoin (in Japanese). 